\title{
On Unpretentious Aesthetic of Eastern and Western Painting Colors
}

\author{
Juan Huangfu \\ Sias International University \\ Zhengzhou University \\ Xinzheng, Henan, China 451150
}

\begin{abstract}
The color language, as a significant element in painting, enjoys strong art expressive force and produces an effect to evoke emotional resonance instantly. The color application of the western painting shares the same expressive way with the subject and simple color pursuit of Chinese traditional ink painting. Artists from both western countries and China are exploring the infinity from the limited colors. The unpretentious color language is characteristic of unpretentiousness, gentleness, reserve and imagination which are similar with ink's features. Since the similarity, the unpretentious color language keeps a foothold in the Chinese painters' palette and greatly matches with Chinese spiritual imagination's color. In this art age of chasing fame and fortune, it is the unpretentious color language that modern artistic works need to draw on and inherit. We need to review the color expression in modern eastern and western paintings, explore the infinity from the limited colors and develop our creative practice.
\end{abstract}

Keywords-unpretentiousness; oil painting's color; ink painting's language power; recovering original purity and simplicity

\section{INTRODUCTION}

With unremitting efforts from numerous scientists and artists, people increasingly comprehend the color principles. Splendid and bright colors can be expressed directly, richly and exaggeratedly in paintings, this moment, unpretentious and reserved colors, like Cinderella, are hidden behind the bright colors. Modern art has abandoned all traditional bondage and criteria. When the colors mean all, we find the latent "crisis" appears secretly. Thus, some paintings leave dazzling appearance alone. The unpretentious colors, however, can touch people to the heart.

\section{CURRENT SituAtion OF MODERn PAINTING'S COLOR}

After 20th century, western modernism, postmodernism, surrealism, futurism and other genres are surging and fastchanging. The traditional recognition boundary of art is so blurred to disappear. Meanwhile, the language methods are diversified and extremely inclusive. As the cultural communication, the art of Chinese painting is deeply impacted. It seems like Chinese painting is flourishing, whether the Chinese oil painting creation or the traditional Chinese painting creation, however, since they are born, suffer unprecedented reproach, criticism and crisis. The art form goes to extremes from pure "visual image" to "game of art form". The visual form of colors has been transferred into colors signifier and signified -- colors refer to content, method and destination. Colors are regarded as pigments' self-being and self-making. The colors even can dissolve and change into nothing on the blank canvas. But excessivefreedom colors' application indicates seems unrestraintly and unduly gorgeous, which makes artists do not know which way to turn and do not know how to express the general appearance of a picture. In order to draw people's attention, some artists choose colors by unscrupulous methods, applying exaggerating and irritating colors to give vent to their passion, focusing on creating good-looking "color effect", searching for high-purity saturation or ornate extremity. The artists are concerned that the unpretentious and simple colors cannot express their own feelings. If so, the colors only can convey visual surface's aesthetics. Nevertheless, the value and meaning of the colors in paintings are weakened.

We usually regard unlimited freedom to apply colors in painting as a strong and distinguished language method. When trying all colors, we are seemingly confined to the rich colors. Excessive freedom renders the colors to retreat to superficial visual stimulus, simple imitation and deliberately mystifying. On the contrary, some unpretentious colors' languages can make the painting picture natural, vivid and unreduplicate. In terms of creation, it does not mean more colors convey richer color sense, neither the high-purity colors convey higher taste of painting pictures, nor the extreme simpleness and nothing to express colors means success. While, applying the rough method, the language could be more powerful and straightforward.

\section{UNPRETENTIOUS COLORING AND CHINESE IMAGE}

"Su" in Chinese itself means natural color, i.e. white or simple and elegant colors, which always show low-purity and low-brightness appearance and places emphasis on "black and white", "proper color" and "grey". The unpretentious colors often derive from putting black and white into a certain color and lowering the purity and brightness: or some mixed colors without any color preference. In each period, both in western paintings and eastern paintings, we can find the shadow from unpretentious 
colors which always shine with their own unique radiance. Through the most commonplace appearance and simplest language, the unpretentious colors can manifest the most powerful force.

\section{A. Plainness of Western Oil Painting}

From simple cognition to in-depth recognition, the development of western oil painting's colors experience from using objective natural colors to subjective emotional colors. People have been repeatedly exploring and practicing how much the color should be used and what the best ratio is between plainness and floridness. Although the colors' value is constantly expanded and changed, some people are fascinated with the plain colors' language.

In the early stage, classical painting belonged to "imitation" and "reappearance" system. That the colors are subordinate to sketch decided the painting picture should be very simple color using in terms of colors' expression. In Renaissance, the natural color view of object color expression made many picture's hue mainly take on brown, which would be simple and elegant like color effect in the candlelight. The general effect of the works showed characteristics of warmth, gravity, simple-color and harmony. In modern paintings, both western countries and China apply rich colors. However, there are also some quality works with simple colors, in which colors and styles of Morandi's works of still life are extremely simplified. His plain and close-tonothing color using makes limited dimension of a picture like a stele without inscription stands in the open field. The scene makes people touched inexplicably. In the painting Still Life created in 1957, some bottles and cans Morandi often depicts huddle in the center of the canvas, taking coldgrey color as a background quietly. There are some differences between the general bluish-grey colors. Thus, the painting is meaningful and delicate. Meanwhile, all of their most bright parts are added warm colors like middle-yellow or light-yellow. Whether the color is yellow or burnt umber, it is not obvious that Morandi adds the color into the painting. The general effect is unified as grey. All kinds of grey colors are detached to materials and show intangible. There exist many changes in the limited canvas. Several unpretentious colors seem very simple and grey, but there are elegant middle colors describing things. Therefore, the whole picture is grave and simple, down-to-earth and low-profile, which create a kind of mystery even Chirico acknowledges. In creation, the simplest and plainest colors become unique and powerful symbol of spirit when painters apply the colors.

\section{B. Black and White in the Chinese Ink Painting}

Chinese traditional painting has its own unique unpretentious color view. The feature of Chinese painting is taking ink as color -- painters like using simple black and white to express objects' color. The painters pursue a natural, tranquil and simple aesthetic. Laozi believes that "iridescent colors cause blindness". Zhuangzi puts that "iridescent colors make eyes dazzling and make the view unclearly". They advocate that colors should be black and white, which develops simple and plain aesthetic thought. Hence, Chinese painting colors choose the simplest black and white to apply, blazing a oriental color road of simple and plain spirit.

The hue of black and white is the simplest color containing various changes. Traditional hue of "Xuan Se" refers to black, a "mother color" which can produce five colors. Oriental paintings do not fully realize the reappearance of the real colors in vision. Chinese traditional painting believes the imitation of colors should not take drawing as destination but attach importance to subjective spiritual creation objects. All of the expression ways should serve "image". Therefore, Chinese traditional painting often divides a blaze of colors, to the biggest extent, into black and white. The color perspective of Chinese ink painting, in fact, is equal to the idea that the use of paint in oil paintings expresses their meaning between "having-and-nothing". Both of them would like to use limitation to express limitless idea and to be pregnant with power in commonplace. If we put the grey from Morandi's oil paintings together with the black and white from Chinese ink paintings, "they are very close and they are into the same realm. That is indeed an impressive art. Thus, whether in western countries or in eastern ones, all of the arts can communicate with each others when they attain to the highest real." says Balthus.

\section{THE FORCE'S CONSTRUCTION OF COLOR'S RELATIONSHIP}

\section{A. Colors' Restriction}

Unpretentious colors' language in construction relationship uses lest colors and the structure is simple and avoids complexity. But less does not mean simpleness. The key factor of color does not count on quantity but on the colors' choose. In Morandi's oil paintings, we find the picture pays more attention to building colors' order, using same type of colors to form stability and peace. The layers of colors are unified in one rhythm and one tune. Chinese ink painting attaches greater importance to avoid rich colors and simplify the colors to black and white. In this expressive method, rational restriction is necessary. Great classical painters thought rich colors' change could diminish the enduring and stable rational model. Back to 4th century, Apelles and his contemporary counterparts invented fourcolor pallet. The four colors only refer to Milos white, Atik yellow, Sinop red and carbon black. Only the 4 colors can be made into 819 colors. But painters are extremely moderate in using colors when creating works. The famous painting Mona Lisa, by Da Vinci, has a simple harmony between typical proper color and brown sepia with brightness, gravity and elegance, which indicates painters have been searching for unpretentious effect in paintings since many years ago. The less the colors are used, the purer and brighter effect of the painting will take on. Excessive colors could easily cause flattering to eyes, resulting in complex and irritating visual perception. Hence, it can disturb people's appreciation aim.

In oriental arts, Chinese people call the painting "danqing" (in Chinese means dark red and green), which indicates colors in Chinese paintings were rich and splendid. In the prime of five-color in Tang Dynasty, the ink painting with black and white sprang up, and the colors went back to 
simpleness after splendour. Oriental paintings do not fully realize reappearance of visual realism color, for the artists found color imitation should not be the destination of drawing. Supported by the conception of image model, the artists chose "black, white and grey" as the axis of painting colors and revealed the essence of the colors from the single black. "Pusu" itself in Chinese means simpleness and unpretentiousness. Rich colors might destroy the characteristics of simpleness and unpretentiousness. Therefore, temperance and effectiveness of using colors are beneficial to expressing mellowness and plainness.

\section{B. Soft Chromaticity Constructs Harmony and Micro- Differential}

The plain colors are generally grayish, low-purity, of characteristic of "between colors and non-colors". The reserve hue itself does not have the ability to express strong colors. The hue, with peaceful, simple and inclusive features, is not obvious and unclear, which make itself in most cases a subsidiary to other colors. And the hue has a good function of cooperation among colors. In terms of activeness and definition, plainness is a kind of reserve and inertia color, while the adjacent colors are easy to make the plain colors get new color sensation. When artists put the unpretentious colors in warm colors, the unpretentious colors will make people feel warm since the surrounding atmosphere. If we put the same grey color into cold colors, it can also show stern and cold light. Each color between could cause dedicate influence and change on each other, which extend the color sensation unlimitedly. The expansion will generate a wide color gamut. The more clumsy and incomplete the colors are, the more visual imagination, understanding and expansion the appreciators will contemplate on. Colors in the reserve and vagueness obtain more possibilities to express their meaning and even surpass the meaning of their own color gamut to become hard to depict their far-reached meaning.

Meanwhile, in the unified and stable tinge the unpretentious colors take advantage the small difference of hue and the weaker micro-differential in lightness to make the painting pictures rich and meaningful. The "microdifferential", in fact, refers to the fact that it is difficult to observe and it is delicate changes. In Morandi's works, if we just appreciate colors separately, they are lacking of energy and vitality. But through smart comparison and combination by Morandi, the simple colors become unbelievable, which produces an effect of liking-purple-but-not-purple, likingblue-but-not-blue and liking-having-but-not-having exquisite and warm color sensation. Utilizing the micro-differential and changes of hue, cold-and-warm, and brightness makes colors affect each other and compare with each other. You could not find the strong comparison between the unified hues, but the whole picture shows extraordinarily delicate and changeable with order and rhythm, constituting a harmonious and mysterious artistic conception with beauty. At the same time, adding the black and white can reduce the chromaticity of pure color, but in the change between blackand-white brightness, it can produce rich grey layers. In Tang Dynasty, Zhang Yanyuan put forward a theory of fivecolor: "using the ink and getting the five colors, and then your can express what you want. That what you want to express is based on the five colors, and then all of the images can be painted through the five colors." On the painting papers, ink with water can get five different changes of ink colors: strong, coke, heavy, light and clean. The colors of black and white can not be reduced, but they can obtain unlimited grey and expressive force when mixing with water. In Wu Costume and Light Color by Wu Daozi, White Cat by Li Gonglin, Ink Leaf and Red Flower by Qi Baishi, the simple colors shine with splendour when getting wellequipped ink and expertise.

In creation, it does not mean the more colors you apply the more color sensation you can express. Neither the higher purity of the color, the higher taste the picture possesses. Not using an extreme or a nihilistic way to express colors means mystery. When the technique is coarse, the language will become more powerful and straightforward. The appropriate construction of the unpretentious colors relationship can express meaning much more than we can imagine.

\section{Practical Significance to Modern Painting Creation Through Research on Unpretentious Colors' Language}

The colors will automatically cause corresponding mind and mental activities, such as behaviour, emotion and spirit etc. By reducing visual stimulus and disturbance, unpretentious colors can pacify people's eyes and minds, lead them to the deep place of the picture and bring the most natural thought and touch which transcend feelings with strong and in-depth spiritual guidance. The unpretentious colors with the features of plainness, non-intensity, reserve and image which are similar to ink's characteristics become painting colors perfectly matching with Chinese spiritual image, which embodies our internal nation's spirit and expresses Chinese artists' "unique language". All of the spiritual wealth will bring a lot of beneficial enlightenment to our modern painting creation.

Chinese oil painter He Duoling persists in simpleness in her pictures during his unremitting efforts. He tries to reduce elements on pictures. His works look simple and obscure, always showing grey-white, grey-blue, grey-brown $\cdots$ without space, without meaning, mixing wall-style or sky-style background and figures. However, when you hold your breath and appreciate his works closely, the thin-painted colors overlap layers by layers. From the top of the picture to the bottom, it looks very flexible and figures in the picture are treated with misty paints so they seem nihilism. For over 50 -year-old He Duoling, his colors in pictures could not be rich and splendid but reserve and simple with delicate and complex colors. Thereby, it can indicate the author's attitude of "pursuit of truth". There are many other painters like Chen Wenji. His new works appear original and purified beauty which is gradually far away with reality and state-of-art and showing indifference and inactivity. Duan Zhengqu's colors in his works are simple but not out of date. The two biggest features in his works are unpretentious language and strong sense of feeling. Zhang Xiaogang uses simplicity of colors to lead to spiritual nostalgia. 
Simple, honest and contemplation, paying attention to connotation are always the excellent quality what Chinese traditional painting possesses People spontaneously put the colors of this quality together with Chinese modern painting, and then generating our own delicate art style. We could further combine Chinese classical art philosophy with the modern painting, using the unpretentious simple colors to carry forward our won national cultural spirit and to blaze a new trial for Chinese modern oil painting and national art.

\section{CONCLUSION}

It is the color that most difficult to explain in painting art. The realization of color's value does not count on whether the colors are gorgeous or not. The several unpretentious colors, once through orderly arrangement and creation by painters, can influence on each other. And the inner world of the mix symbolizes another deeper realm. The unpretentious colors can make us conduct more contemplation. Our art creation and research should return to the spiritual essence of art, which is what modern art creation needs to draw on and inherit from.

\section{REFERENCES}

[1] Zong Baihua: "Aesthetics in Walk", Shanghai People's Publishing House, ed. 1985.

[2] Pan Tianshou: "Aesthetics of Color ", Beijing: People's Fine Arts Publishing House, ed.1998.

[3] Ouyang Ying, Pan Yaochang: "Foreign Fine Arts History", the Publishing House of China Academy of Fine Arts, ed.1997.

[4] Wang Huabin: " Chromatics of Painting", People's Fine Arts Publishing House, ed.1996.

[5] Xu Jiang, Jiao Xiaojian: "Anthology of Figurative Expressionism Painting " , the Publishing House of Chinese Academy of Fine Arts, ed. 2002 